\title{
AVALIAÇÃO DAS UNIVERSIDADES BRASILEIRAS AS POSSIBILIDADES DE AVALIAR E AS DIFICULDADES DE SER AVALIADO
}

\author{
Jorge Luiz Lordêlo de SALEs Ribeiro*
}

Recebido: jun. 2010

Aprovado: ago. 2010

*Psicólogo, Mestre em Lingüística e Doutor em Educação pela Universidade Federal da Bahia, é professor adjunto do Instituto de Psicologia da UFBA. E-mail: josales@ufba.br

Resumo: As dificuldades decorrentes da elaboração e implementação de um sistema de avaliação para as instituições de ensino superior no Brasil - IES são grandes e complexas, não só pelas dificuldades inerentes ao ato mesmo de avaliar, como também pelas características do Sistema Federal de Ensino Superior Brasileiro, quais sejam: a quantidade de IES, as suas diferentes formas de constituição e tamanho, a concentração das IES nas regiões geográficas mais desenvolvidas do país, etc. As IES, por sua vez, experimentam dificuldades não menos importantes, na medida em que sofrem diretamente as consequências da divulgação dos resultados, e reagem defensivamente, dificultando a visibilidade dos formuladores das políticas de avaliação. Este trabalho pretende apontar alguns aspectos enfrentados pelos avaliadores e avaliados nesta difícil tarefa, e refletir sobre o papel da avaliação das IES no Brasil, tanto no contexto das políticas de expansão do sistema de ensino superior, como das políticas de manutenção da sua qualidade.

Palavras-chave: Avaliação institucional. Avaliação universitária. Políticas de avaliação das universidades.

\section{EVALUATION OF THE BRAZILIAN UNIVERSITIES - THE POSSIBILITIES OF EVALUATION AND THE DIFFICULTIES OF BEING EVALUATED}

Abstract: There are difficulties arising from the preparation and implementation of an evaluation system for higher education institutions in Brazil - HEI are large and complex, not only by the difficulties inherent in the very act of evaluating, as well as the characteristics of the Brazilian Federal System of Higher Education, namely: the number of HEI, the different formation patterns and sizes, the concentration of HEI in geographical areas located in more developed regions, etc... The Higher Education Institutions, in turn, experience difficulties that are no less important, to the extent that they directly suffer the consequences of the dissemination of results, and react defensively, making the visibility of evaluation policy-makers difficult. This study intends to point out some issues faced by evaluators and evaluated in this difficult task, and to reflect on the role of the evaluation of the HEI in Brazil, both in the context of expansion policies for the higher education system, as well as in the quality maintenance policies.

Key words: Institutional evaluation. University evaluation. University evaluation policies.

\section{INTRODUÇÃO}

A primeira coisa que se pensa diante da palavra avaliação é a finalidade/ utilidade dos seus resultados, ou seja, há uma estreita relação entre a utilização que se fará dos resultados da avaliação e os procedimentos e modelo adotados. Isto quer dizer que a avaliação não é um empreendimento isento e justificado por si mesmo, não é uma simples aplicação de um método de conferência 
da produtividade ou da eficiência de uma instituição. Ao contrário, avaliar é imprimir uma orientação, é conferir o grau de adesão a um ponto de vista, é, portanto, parte de um propósito, de uma política, como bem destaca Dias Sobrinho (2002).

Deste ponto de vista, para avaliar uma instituição de ensino superior é preciso estar inteirado da sua missão institucional, dos seus objetivos e finalidades, mas é preciso, também, estar inteirado da política de avaliação adotada pelos órgãos governamentais, dos critérios e indicadores adotados para examinar a qualidade da educação superior, bem como das regras estabelecidas para monitorar o sistema de educação superior.

De fato, a avaliação de instituições universitárias traz à tona necessariamente a difícil discussão de conceitos e concepções sobre ensino, aprendizagem, gestão e políticas de ensino. Difícil, porque discutir estes temas implica, necessariamente, em estabelecer e demarcar posições políticas e ideológicas quase sempre inconciliáveis. Um bom exemplo disso é o conceito de qualidade. Vroeijenstijin (1996) diz que procurar uma definição para qualidade é perda de tempo. De fato, são inúmeras as definições, enfocando aspectos diferentes daqueles que poderiam ser tomados apenas como resultado de uma atividade. Quando aplicado ao ensino superior, o problema assume enorme proporção, pois vários são os aspectos que podem ser enfocados para expressar qualidade. Desde o número de alunos, o tempo de conclusão dos cursos, a relação entre o planejamento e a execução das atividades, a qualificação do corpo docente, a produção científica dos alunos e dos professores, taxa de reprovação, taxa de conclusão de curso. Portanto, qualidade não está associada apenas a resultado, como também a produto, a satisfação, a eficácia, a precisão etc.

Preocupada com a utilização do termo qualidade na educação superior, Santana (2007, p. 83) estabelece uma relação entre a avaliação e a utilização do termo qualidade:

O papel de Estado como avaliador da educação superior se consolidou com a utilização mais incisiva do termo qualidade na legislação e no discurso oficial sobre ensino superior. A legislação educacional brasileira, no artigo 206 da Constituição e no artigo $4^{\circ}$ da LDB, determina que a "garantia de padrão de qualidade" é um dos princípios da educação. Mas [...] não deixa claro o que significa "padrão de qualidade”. Qualidade do quê? Para quê? Para quem? Como? [...].

Algumas situações da educação superior, quando traduzidos em indicadores, destacam importantes aspectos da vida acadêmica. Outras, no entanto, destacam 
situações paralelas à prática acadêmica, como por exemplo, o uso racional dos recursos ou a relação de consumo que se estabelece entre o aluno e a universidade, numa flagrante alusão ao modo de produção capitalista incorporado ao ensino, situações essas tão bem discutidas por Boaventura Sousa Santos (2003), e que, de certo modo, prejudica o entendimento da qualidade no ensino superior, na medida exata em que se transpõe inadvertidamente a lógica do trabalho administrativo para a práxis acadêmica, o que Lima (1997), chamou de educação contábil. Os critérios capazes de indicar o nível de qualidade de uma instituição universitária, como foi visto, são muitos e não há consenso sobre a importância de cada um deles. $\mathrm{O}$ entendimento do próprio conceito de qualidade é um dos obstáculos enfrentados pelas comissões para avaliar as instituições universitárias.

De outra parte, as avaliações das instituições universitárias são realizadas por comissões, compostas normalmente por professores, técnicos administrativos e alunos, convidados ou indicados pelos seus dirigentes que, em paralelo às suas atividades de rotina, assumem o trabalho de planejamento e execução da avaliação institucional. Via de regra, a aceitação desta tarefa, quando não por imposição do mantenedor ou chefe imediato (sobretudo nas instituições particulares), está relacionada a interesses pessoais pelo tema, boa vontade, ou mesmo, vontade de contribuir com o desenvolvimento institucional, como indica o trabalho realizado por Ribeiro (2008). Torna-se um grande desafio, portanto, a capacitação de mão de obra especializada para a realização da avaliação das instituições universitárias. Apesar dos desafios e das dificuldades, há um nítido reconhecimento da importância da avaliação na atualidade. Seja qual for o modelo de avaliação adotado, sejam quais forem os critérios determinados, o reconhecimento da necessidade é consensual, apesar de toda dificuldade da tarefa. Mas porque a avaliação tornou-se tão necessária e aceita?

Talvez seja justo pensar que o consenso em torno da avaliação foi produto, de um lado, da capacidade de demonstração da utilidade dos seus resultados, seja para conhecimento da realidade do sistema de ensino superior, seja para prestar contas à sociedade, seja para subsidiar decisões políticas e administrativas neste campo. E, de outro lado, pressionado pela reforma do Estado, a escassez de recursos para financiamento dos altos custos gerados pelos sistemas de ensino superior exige, cada vez mais, como contrapartida, a qualidade dos cursos e a eficiência das universidades.

Os argumentos apontam, portanto, para a convergência entre preocupações de ordem acadêmicas e preocupações de ordem administrativas. Compreender as consequências dessa convergência no campo da avaliação universitária 
é o ponto de partida para refletir acerca dos problemas e desafios do ensino superior brasileiro na atualidade e o papel da avaliação como instrumento de diagnóstico e de intervenção sobre o Sistema Federal de Ensino Superior. Tal compreensão proporciona ao Estado a possibilidade de regulação e supervisão, e às Instituições de Ensino Superior - IES, as possibilidades de crescimento e aprimoramento da sua qualidade. O objetivo deste trabalho é examinar algumas dificuldades enfrentadas pelo Governo Federal e pelas instituições universitárias para realizar a avaliação institucional, buscando, assim, contribuir com o aperfeiçoamento do Sistema Nacional de Avaliação da Educação Superior - SINAES.

\section{A AVALIAÇÃO DO ENSINO SUPERIOR NO BRASIL}

Nos últimos 15 anos, as grandes e rápidas transformações econômicas, políticas e sociais ocorridas ao redor do mundo, sobretudo na produção, circulação e distribuição das riquezas, refletiram-se na diminuição da capacidade de gerenciamento e de sustentação das atividades básicas e essenciais por parte do Estado. As instituições, principalmente as universitárias, demoraram a compreender isto e reagiram fortemente para manter as suas verbas, a sua autonomia e, principalmente, o seu modo de gerenciamento. De outra parte, o Estado, dando continuidade ao seu projeto de modernização, adotando cada vez mais o ponto de vista neoliberal na expectativa de se incorporar a uma nova ordem mundial, imprimiu uma rígida contenção orçamentária às instituições públicas e incentivou a expansão do sistema de ensino superior pelo setor privado. A avaliação, então, é tomada como elemento norteador desse processo, como defende Durhan (2003). Na década de 90, no auge da expansão, o Sistema Federal de Ensino Superior brasileiro era submetido a sete diferentes formas de avaliação:

1) Avaliação para autorização de curso

2) Avaliação para reconhecimento de curso

3) A avaliação das Condições de Oferta

\section{4) Exame Nacional de Cursos}

5) Análise das Condições de Ensino

6) Questionário sobre as condições sócio-econômicas do aluno e a sua opinião sobre as condições de ensino do curso freqüentado.

7) Avaliação Institucional dos Centros Universitários 
O ENC - Exame Nacional de Curso, popularmente conhecido como "Provão", tornou-se o centro da atenção da mídia, que entendeu ser este componente da avaliação uma fiel fotografia da qualidade das instituições de ensino superior, uma vez que media o desempenho do aluno, considerado o principal "produto" da atividade universitária. Apesar dos equívocos, a divulgação dos resultados do ENC causou, principalmente às instituições privadas de pequeno porte, que disputam a sobrevivência num ambiente muito competitivo, benefícios e malefícios. O Exame Nacional de Cursos cumpriu um importante papel: o de questionar os projetos de curso e, em consequência, a idéia de qualidade no ensino. À medida que se expandia para outros cursos, pretendendo alcançar a totalidade dos cursos de graduação, o Exame Nacional de Curso passou a ser destacado nos processos de renovação de reconhecimento de cursos, tornandose um poderoso instrumento de orientação da expansão do Sistema Federal de Ensino Superior brasileiro e de regulação, pois os seus resultados passaram a ser considerados suficientes para o reconhecimento dos cursos (Lei N. 9.131/95).

Alguns autores, no entanto, acreditam que a forma centralizada de implementação do Exame Nacional de Cursos e as consequências da divulgação dos seus resultados mudaram a relação do Estado com a avaliação, como assinala Gomes (2003, p. 144) "o papel regulador do MEC que passa a exercer as funções do 'Estado Avaliador', descrito por Neave (1988)". A reação da comunidade universitária foi imediata e muitos estudantes se recusaram a fazer o "provão". Mas, ao longo do tempo, terminaram por ceder às pressões tanto do Governo como da mídia que divulgava os resultados positivos das IES participantes, em detrimento das que não participavam do processo.

A forma como o processo de avaliação foi posto em prática nos anos 90 , sobretudo no que diz respeito à falta de participação da comunidade universitária no processo, indica uma política do tipo Top Down ${ }^{1}$, onde o governo define os parâmetros de avaliação do sistema e submete as instituições ao processo. Esta forma de concepção e implementação da política de avaliação do Sistema Federal de Ensino Superior no Brasil reproduz uma tendência apontada por Albaek (apud FARIA, 2005, p. 98) sobre os processos de avaliação nos EUA nos anos 60, quando prevalecia a função de subsidiar o planejamento de polí-

1 O processo de implementação de políticas com abordagem top down tem como principal característica a separação entre os planejadores, que elaboram as políticas e os implementadores que as executam, sem ter participado da sua elaboração. Enquanto a abordagem bottom up, ao contrário, busca o envolvimento de todos os participantes, convencendo-os acerca dos benefícios da política. A distinção entre as duas abordagens pode assim ser entendida: "Simplificadamente, pode-se afirmar que a abordagem top down centra-se na questão dos mecanismos de controle sobre os agentes implementadores para que os objetivos da política sejam atingidos. Por sua vez, a abordagem bottom up enfatiza os incentivos que induzem os agentes implementadores a aderir normativa e operacionalmente aos objetivos da política". (SILVA, 2000, p. 8) 
ticas públicas, servindo, portanto, aos formuladores de políticas e aos gerentes controladores do sistema.

Os processos de avaliação são, portanto, políticas públicas com grande capacidade para promover mudanças e adequações nos sistemas de ensino frente às demandas sociais. Prova disso é que o governo Luiz Inácio Lula da Silva colocou a avaliação institucional como o eixo da reforma universitária. A avaliação, uma primeira etapa implementada que, juntamente com as políticas afirmativas, visam a democratização do acesso ao ensino superior, a ampliação da oferta para camadas menos favorecidas da sociedade e otimização dos recursos investidos, através da modernização dos processos de gestão universitária. As medidas devem repercutir no setor privado, com efeitos na redução da taxa de ociosidade do sistema e na democratização da gestão, inclusive com a maior participação do corpo social da instituição e da comunidade externa.

\section{O SISTEMA NACIONAL DE AVALIAÇÃO DA EDUCAÇÃO SUPERIOR - SINAES}

Para cumprir essas finalidades, o Governo Federal concebeu o Sistema Nacional de Avaliação da Educação Superior - SINAES². Valendo-se das experiências anteriores, o SINAES foi elaborado por uma comissão especialmente constituída para este fim, a partir de uma ampla discussão envolvendo a comunidade universitária e outros segmentos da sociedade civil organizada, orientada por uma abordagem de implementação de políticas bottom up ${ }^{3}$, contrária, portanto, à abordagem utilizada pelo ENC, no governo anterior.

O SINAES foi uma tentativa bem sucedida de reunir, num só momento, todas as faces da avaliação universitária, adotando uma visão sistêmica, integrando todos os dados obtidos em diferentes práticas avaliativas. Se por um lado isso representa racionalidade nos procedimentos, resultando em economia de tempo e de recursos, por outro lado, representa também dificuldades na adequação da sistemática de avaliação às características do Sistema Federal de Ensino Supe-

2 . "Sistema Nacional de Avaliação da Educação Superior - SINAES: Bases para uma Nova Proposta de Educação Superior", documento apresentado em 2004 pela Comissão Especial da Avaliação da Educação Superior-CEA, presidida pelo Prof. Dr. José Dias Sobrinho, (UNICAMP), instituída em maio de 2003, pelo então Ministro da Educação, Cristovam Buarque, com a finalidade de "analisar, oferecer subsídios, fazer recomendações, propor critérios e estratégias para a reformulação dos processos e políticas de avaliação da Educação Superior e elaborar a revisão crítica dos seus instrumentos, metodologias e critérios utilizados", (BRASIL, 2004). Em abril de 2004 a Lei 10.861, institui o Sistema Nacional da Educação Superior - SINAES, publicada no Diário Oficial da União $\mathrm{n}^{\circ} 72$ de 15 de abril de 2004.

3 . Ver distinção entre as abordagens top down e bottom up na nota 1. 
rior do país. Trata-se de um sistema heterogêneo, caracterizado pela presença de instituições públicas e privadas, constituídas como Universidades, Centros Universitários e Faculdades, com diferentes tamanhos e naturezas administrativas. Ademais, o Brasil é um país com uma população relativamente jovem, com baixo nível de escolarização e com precário poder aquisitivo. Cerca de $49 \%$ da população economicamente ativa ganham em torno de três salários mínimos por mês, de acordo com os dados do IBGE (2004). O Sistema de Ensino Superior brasileiro tem 5.080.056 alunos matriculados em 2.252 Instituições de Ensino Superior, distribuídos em diferentes tipos de instituições, conforme demonstrado a seguir:

Tabela 1. Matrículas na Educação Superior por Organização Acadêmica - 2007

\begin{tabular}{lrr}
\hline Organização Acadêmica & Matrículas & \multicolumn{1}{c}{$\%$} \\
\hline Universidades & 2.685 .628 & 56,9 \\
Centros Universitários & 720.605 & 14,8 \\
Faculdades & 1.673 .823 & 4,8 \\
Total & 5.080 .056 & 100,0 \\
\hline
\end{tabular}

Fonte: INEP (2008)

Ainda de acordo com o INEP, dados de 2008, as instituições privadas respondem por $75 \%$ das matrículas e os $25 \%$ restantes estão vinculados a instituições públicas federais, estaduais e municipais. Apenas $8,1 \%$ são universidades, em sua maioria instituições públicas. Os centros universitários representam 5,5\% do total e a grande maioria das IES brasileiras é constituída por faculdades $(73,2 \%)$, de pequeno porte, (menos de 1.000 alunos), pertencentes ao setor privado $(94,2 \%)$. Outro aspecto importante é que dos 18.644 cursos vinculados ao Sistema de Ensino Superior, 10.475 estão nas universidades.

Esses aspectos exigem do processo de avaliação e principalmente dos avaliadores a compreensão das consequências dessas características sobre o bom funcionamento dos cursos e das instituições formadoras. Avaliar, conforme foi destacado anteriormente, não pode ser a aplicação direta e mecânica de uma metodologia, nem tampouco a obediência cega às diretrizes e aos roteiros preestabelecidos. Será necessário contextualizar o processo de avaliação, discernir o que significa um determinado resultado para uma determinada instituição, compreender como cada indicador avaliado pode contribuir para a boa consecução de uma proposta acadêmica e usar o bom senso para superar os muitos desafios postos na relação entre os avaliadores e ao avaliados. 


\section{OS DESAFIOS DO SINAES}

O primeiro grande desafio a ser enfrentado pelo SINAES é avaliar um sistema de ensino superior muito grande, heterogêneo, distribuído irregularmente por cinco regiões geográficas muito diferentes uma das outras, utilizando o mesmo modelo, os mesmos critérios e princípios para avaliação. Esta situação produz consequências diretas sobre a finalidade da avaliação. Nas regiões Sul e Sudeste, por exemplo, concentram-se cerca de $66 \%$ das IES brasileiras, consequentemente, aí estão concentrados o maior número de alunos, os professores mais capacitados e as IES cientificamente mais produtivas, capazes de atrair grande parte do financiamento destinado ao ensino superior brasileiro. Qual o papel da avaliação acerca deste aspecto? A avaliação deve promover condições para equalização do Sistema, ou deve se constituir num poderoso sinalizador de eficácia e eficiência, para subsidiar as decisões sobre aplicação dos recursos financeiros para o ensino superior? Esta questão não foi bem definida no âmbito da avaliação, pois, ao final do primeiro ciclo de avaliação do SINAES, a política de financiamento das IES pouco se alterou. No que diz respeito às Universidades Federais, a distribuição dos recursos oriundos do Programa de Apoio a Planos de Reestruturação e Expansão das Universidades Federais - REUNI, por exemplo, não levou em consideração os dados da avaliação institucional.

O outro desafio é desenvolver um só instrumento capaz de avaliar as diferentes IES, tanto em relação ao tamanho: IES de pequeno, médio e grande portes, como em relação á natureza administrativa: IES públicas e privadas. No caso do SINAES, em especial, as dez dimensões da avaliação propostas pela CONAES parecem mais relacionadas com as IES privadas, de pequeno porte. Por outro lado, a construção dos instrumentos de avaliação, que devem levar em consideração as dez dimensões, parece tomar como referência, em muitos aspectos, as universidades de grande porte. A adoção de certos critérios e, sobretudo, as exigências quanto à produção de conhecimento e regime de trabalho do corpo docente, por exemplo, indicam claramente esta tendência. Esta questão foi parcialmente resolvida com a opção por manter certos indicadores aplicáveis às universidades e não aplicáveis às faculdades. Porém, não resolve as situações decorrentes do tipo de contrato de trabalho do corpo docente e do seu nível de qualificação, dos aspectos financeiros, da imagem da instituição etc.

A dificuldade com o instrumento é tão grande quanto treinar avaliadores capazes de compreender e respeitar as diferenças institucionais, de exercer bem o seu papel de agente transformador, próprio das avaliações de caráter formativa e, ao mesmo tempo, exercer o papel de agente fiscalizador, próprio das 
avaliações de caráter regulatório, cumprindo assim a dupla função do Estado, quais sejam: autorizar, credenciar, reconhecer e renovar o reconhecimento de cursos e instituições de ensino superior, (função regulatória); avaliar, incentivar e garantir a qualidade dos cursos oferecidos pelas instituições de ensino superior, (função formativa).

De fato, estas parecem ser as duas maiores dificuldades do SINAES: o treinamento e capacitação dos avaliadores para regular o Sistema, e o entendimento do que seria qualidade e quais os indicadores seriam utilizados para garantir e incentivar o aprimoramento das IES.

A criação de um banco de avaliadores (BASis), que cadastrou avaliadores de todas as regiões do país, não foi suficiente para vencer esta dificuldade. Os critérios exigidos para inscrição no cadastro não garantiam a experiência com avaliação institucional (Portaria 073/2002 INEP; Edital de Credenciamento 01/2006; Portaria 1.027/2006 MEC). Além disto, a quantidade de avaliadores necessária para realizar avaliação em mais de duas mil instituições é muito grande, o que significa, obviamente, dificuldade de treinamento. As constantes prorrogações dos prazos estabelecidos para realização das avaliações externas são um bom indicador desta dificuldade (Portaria Normativa No 1/2007 MEC; Portaria Normativa No 6/2007 MEC; Portaria Normativa No 40/2007 MEC). A solução para minimizar o problema veio em forma de um indicador de qualidade da IES (Índice Geral de Cursos - IGC), desobrigando, assim, a visita in loco de avaliadores para aquelas IES que obtiverem um IGC considerado aceitável. Porém, não há uma relação bem definida entre as exigências que os avaliadores farão das IES nas suas visitas in loco com os resultados dos índices de qualidade alcançados no IGC. Portanto, não há garantia de que a ideia de qualidade traduzida no IGC seja a mesma ideia de qualidade defendida pelos avaliadores institucionais quando examinam as IES.

As dificuldades com o treinamento e com a compreensão dos processos avaliativos por parte dos avaliadores ad hoc do INEP/MEC se aplicam igualmente aos avaliadores internos, atores institucionais responsáveis pela auto-avaliação nas IES. Esta questão torna-se muito importante, pois o elemento centralizador do SINAES é a avaliação interna ou auto-avaliação das IES. Em cumprimento à Lei 10.861 de 2004, cada instituição de ensino superior criou uma Comissão Própria de Avaliação - CPA, responsável pela concepção e implementação da auto-avaliação ou avaliação interna. As IES tiveram relativa liberdade para a composição dessas comissões. De acordo com os depoimentos apresentados nas oficinas e seminários regionais promovidas pela CONAES, INEP e MEC, algumas IES privilegiaram docentes com experiência em avaliação, noutros 
casos o interesse pelo tema foi o elemento norteador. Noutros, ainda, a representatividade e legitimidade dos componentes da CPA foram aspectos destacados. Almeida Júnior (2005) estudou o perfil dos coordenadores das CPAs cadastradas no INEP até dezembro de 2004 e identificou que a maioria dos coordenadores cadastrados era de IES privadas e $62 \%$ deles eram docentes. Embora em menor número, identificou também como coordenadores, membros da administração, da sociedade civil e, até mesmo, estudantes. Este dado é muito importante, pois dependendo da função exercida na instituição, a visão e o entendimento do processo de avaliação serão diferentes. Esta, certamente, será uma dificuldade adicional para o treinamento desses coordenadores. De fato, após os seminários realizados pelo INEP e pela CONAES para capacitar os coordenadores de CPAs, quase a metade dos participantes mostrou-se insatisfeita em relação aos esclarecimentos sobre as dimensões, os instrumentos e diretrizes do SINAES (ALMEIDA JÚNIOR, 2005).

Por outro lado, apesar da predominância de docentes na coordenação das CPAs, Assis e Oliveira (2009) estudando os efeitos das políticas de avaliação sobre as práticas pedagógicas, ressaltam que cerca de $72 \%$ dos docentes desconheciam a proposta do SINAES, o que significa dizer que, mesmo sendo docentes, os coordenadores não conseguiram uma boa sensibilização entre os seus pares. Andriola (2005) já havia chamado a atenção para este fato, apontando a sensibilização da comunidade acadêmica e participação dos atores institucionais como os principais desafios a ser enfrentados palas comissões próprias de avaliação.

\section{CONSIDERAÇÕES FINAIS}

A partir das informações disponíveis nos sites das IES, em relatórios e mesmo em artigos publicados, é possível pensar que os efeitos decorrentes da implementação do SINAES recaíram, sobretudo, nas instituições de ensino superior privadas, de pequeno porte. É provável que o sistema de avaliação, sendo apresentado em forma de Lei, tenha produzido um movimento nas IES para a composição das comissões próprias de avaliação, para indicação dos seus respectivos representantes, bem como para a elaboração dos projetos e relatórios de avaliação, e que este movimento tenha gerado uma maior aproximação dos atores institucionais, exigido a elaboração dos documentos institucionais que norteiam a vida acadêmica, tais como projeto pedagógico, estabelecimento da missão institucional e o projeto político pedagógico. Porém, o maior ganho institucional está na proposição de um modelo de gestão baseado no plane- 
jamento estratégico, que surge quase que naturalmente à medida que a IES adota as diretrizes de avaliação do SINAES. Este efeito dificilmente poderá ser sentido nas instituições públicas, de grande porte. Pode-se dizer, então, que o alvo principal do SINAES são as instituições privadas, de pequeno porte.

Entretanto, os principais efeitos esperados, a regulação e o aprimoramento da IES, não mostram sinais de evidência tão claros. No que diz respeito à regulação, ainda é cedo para compreender os seus efeitos, pois os ajustes necessários para corrigir eventuais pontos fracos detectados numa IES após a conclusão dos ciclos de avaliação demandam um tempo maior. Em relação ao aprimoramento da IES, os resultados podem ser utilizados rapidamente e os efeitos podem ser imediatos. As constantes indicações da falta de institucionalização dos resultados da avaliação (RIBEIRO, 2008; CARNEIRO; NOVAES, 2008; PEIXOTO, 2009), apontam para uma ritualização da avaliação, visando o estrito cumprimento da Lei.

No que tange às dificuldades operacionais do SINAES, o problema mais grave, como foi visto, é a seleção e treinamento de avaliadores. Um curso de 30 horas, como foi oferecido aos avaliadores, certamente não é suficiente para treiná-los adequadamente. Além disso, falta indicar com clareza o seu papel quando examina uma instituição: ele estará a serviço do seu aprimoramento, portanto, juntando-se ao esforço dos corpos docente, discente e técnico-administrativo da IES para construir uma instituição melhor, ou estará a serviço do Ministério da Educação, averiguando e fiscalizando as condições descritas no projeto pedagógico, através da dinâmica do funcionamento institucional? Serão, assim, duas diferentes posturas dificilmente exercidas simultaneamente pela mesma pessoa.

As comissões próprias de avaliação, por sua vez, são constituídas por pessoas que se interessam pela avaliação e compreendem a sua importância, mas não são capacitadas para colocá-la em prática. Não têm recursos, muitas vezes, para envolver toda a instituição numa discussão sobre avaliação, estabelecendo, assim os critérios e indicadores de qualidade do trabalho institucional. Como consequência, as pessoas participam da avaliação, mas desconhecem os seus objetivos e finalidade e não percebem as repercussões da avaliação sobre o seu trabalho.

Outros pontos negativos não menos importantes podem, ainda, ser mencionados. Um deles é o conflito gerado pela duplicidade de funções, presente nos documentos oficiais da CONAES/INEP ${ }^{4}$ : por um lado, expressam a

4 Os documentos oficiais da CONAES/INEP são as "Diretrizes para a Avaliação das Instituições de Educação Superior”, publicadas em 2004 e o "Roteiro de Auto-Avaliação Institucional”, também publicado em 2004. 
preocupação com as diferenças institucionais, com a responsabilidade social, com a participação democrática do corpo social e da sociedade civil organizada nos processos de avaliação institucional e, por outro lado, indicam um instrumento ${ }^{5}$ único para avaliação externa, pré-definindo os pesos e valores para cada dimensão, adotando o PDI - Plano de Desenvolvimento Institucional e do PPI - Projeto Político Pedagógico como referências para a avaliação institucional, e produzindo quase que uma interferência na gestão acadêmica das IES, principalmente as pequenas instituições particulares, como já foi discutido. Este conflito pode ser notado, ainda, nos encontros ${ }^{6}$ promovidos pela CONAES/INEP/MEC para capacitação dos coordenadores de CPA, sempre marcados pela desconfiança entre as partes. Os coordenadores, que insistiam em obter garantias em relação à postura dos avaliadores ad hoc acerca das dificuldades que as IES experimentariam para dar conta das exigências contidas nos manuais e diretrizes do INEP; e os representantes da CONAES, do INEP e do MEC, que tentavam tranquilizar os representantes das IES, indicando a necessidade de se instituir uma nova cultura de avaliação, capaz de respeitar as diferenças e especificidades das IES e dos contextos em que elas estão inseridas, mas sem abdicar da função regulatória da avaliação institucional. Esta desconfiança era ressaltada exatamente pelo desconhecimento dos critérios que seriam utilizados pelo INEP para avaliar as IES, pois, àquela altura, não havia ainda nenhum documento que definisse a sistemática da avaliação externa a ser adotada. Portanto, não havia uma ideia objetiva dos indicadores que seriam utilizados para examinar a qualidade, nem de como esses indicadores seriam tratados. $\mathrm{O}$ documento dando conhecimento acerca do instrumento e dos critérios que seriam utilizados para avaliação externa só foi apresentado em novembro de 2005, quando todas as IES já haviam encaminhado ao INEP os seus projetos de avaliação interna e as IES com até 500 alunos já haviam, inclusive, concluído e enviado ao INEP os seus relatórios de avaliação interna.

Certamente as autoridades educacionais brasileiras terão um farto material para repensar e aperfeiçoar os processos de avaliação da educação superior.

5 Documento publicado pela CONAES/INEP em novembro de 2005, intitulado "Avaliação Externa de Instituições de Educação Superior: diretrizes e instrumento".

6 ACONAES, juntamente com o INEP/MEC, promoveram encontros regionais para capacitação das CPA - Comissões Internas de Avaliação, para apoio à auto-avaliação e para elaboração do relatório. Os encontros aconteceram em Brasília, São Paulo , Florianópolis e Salvador, reunindo representantes das IES por região geográfica e por tamanho das IES. 
Terão oportunidade de aprender com a própria experiência. Porém o ponto de partida deverá ser uma discussão ampla e participativa do que entendemos por qualidade da educação superior e de como capacitar pessoas, no âmbito dos órgãos governamentais e no âmbito das IES, para avaliar.

\section{REFERÊNCIAS}

ALMEIDA JÚNIOR, Vicente de Paula. O processo de implementação das Comissões Próprias de Avaliação (CPAs): ações desenvolvidas e perfil dos coordenadores. In: RISTOFF, Dilvo; ALMEIDA JUNIOR, Vicente de Paula (Orgs.). Avaliação participativa: perspectivas e desafios. Brasilia: INEP, 2005. p. 39-57.

ANDRIOLA, Wagner B. Desafios e necessidades que se apresentam às Comissões Próprias de Avaliação (CPAs) das instituições de ensino superior visando à implementação do Sistema Nacional de Avaliação da Educação Superior (SINAES). In: RISTOFF, Dilvo; ALMEIDA JÚNIOR, Vicente (Orgs). Avaliação participativa, perspectivas e desafios. Brasília: INEP, 2005. p. 57-70.

ASSIS, Lúcia M. de; OLIVEIRA, João F. Repercussões das políticas públicas para a avaliação das IES na prática pedagógica de professores em instituições privadas. Avaliação, Campinas, Sorocaba, v. 12, n. 1, p. 111131, mar. 2007.

BRASIL, Lei 10.861 de 14 de abril de 2004, Diário Oficial da República Federativa do Brasil, Poder Executivo, Brasília, DF, n. 72, abr. 2004.

BRASIL. SINAES. Sistema Nacional de Avaliação da Educação Superior: da concepção à regulamentação. Brasília, 2004.

CARNEIRO, Breno Pádua; NOVAES, Ivan. As comissões próprias de avaliação frente ao processo de regulação do ensino superior privado. Avaliação, Campinas, Sorocaba, v. 13, n. 3, nov. 2008. Disponível em: <http://www.scielo.br/scielo >. Acesso em: 14 ago. 2010.

CONAES - Comissão Nacional de Avaliação da Educação Superior. Diretrizes para auto- avaliação das instituições de ensino superior. Brasília: CONAES, 2004. 
DIAS SOBRINHO, José. Educação e avaliação: técnica e ética. In DIAS SOBRINHO, José; RISTOFF, Dilvo. (Orgs.). Avaliação democrática: para uma universidade cidadã. Florianópolis: Insular, 2002.

DURHAN, Eunice Ribeiro. Autonomia, controle e avaliação. In MORHY, Lauro (Org.). Universidade em questão. Brasília: Ed. UnB, 2003. p. 275 300 .

FARIA, Carlos Aurélio Pimenta de. A política de avaliação de políticas públicas. Rev. Bras. Ciências Sociais, São Paulo, v. 20, n. 59, p. 97-109, out. 2005.

GOMES, Alfredo Macedo. Exame nacional de cursos e política de regulação estatal do ensino superior. Cadernos de Pesquisa, São Paulo, n. 120, p. 129149, 2003.

IBGE. Orientações Gerais para o Roteiro da Auto-Avaliação das IES. Brasília, 2004.

IBGE. Resumo técnico: censo da educação superior 2008 - dados preliminares. Brasília, 2009.

LIMA, Licínio. O paradigma da educação contábil: políticas educativas e perspectivas gerencialistas no ensino superior em Portugal. Rev Bras de Educação, São Paulo, n. 4, p. 43-59, jan./abr. 1997.

PEIXOTO, Maria do Carmo de Lacerda. A avaliação institucional nas universidades federais e as comissões próprias de avaliação. Avaliação, Campinas, Sorocaba, v.14, n.1, mar. 2009. Disponível em: <http://scielo.br/ scielo>. Acesso em: 19 jul. 2010.

RIBEIRO, Jorge Luiz Lordêlo de Sales. Características da implementação do sistema de avaliação da educação superior (SINAES) em instituições de ensino superior. 2008. 266 p. Tese (Doutorado) - Universidade Federal da Bahia, 2008.

SANTANA, Flavia Feitosa. A dinâmica da aplicação do termo qualidade na educação superior brasileira. São Paulo: Senac, 2007.

SANTOS, Boaventura de Sousa. Pela mão de alice: o social e o político na pós-modernidade. São Paulo: Cortez, 2003. 
SILVA, Pedro Luiz Barros; MELO, Marcus André Barreto. O processo de implementação de políticas públicas no Brasil: características e determinantes da avaliação de programas e projetos. Campinas: Núcleo de Estudos de Políticas Públicas - Universidade Estadual de Campinas, 2000. (Caderno n. 48).

VROEIJENSTIJIN, A. L. Melhoria e responsabilização: navegando entre Cila e Caríbdis. Manual de Avaliação Externa da Qualidade no Ensino Superior. Brasília: CRUB, 1996. Estudos e Debates, n. 18. 